França, Liliana Segnini aborda as especificidades das condições de trabalho dos/as trabalhadores/ as artísticos/as em música e dança, numa perspectiva de gênero e da divisão internacional do trabalho. Aparecida Neri de Souza analisa, em perspectiva comparada Brasil-França, as relações e condições de trabalho de professores e professoras de escolas técnicas e a maneira pela qual estas são informadas por representações construídas pelos próprios profissionais acerca da profissão. Sylvie Schweitzer propõe colocar as mudanças verificadas no acesso das mulheres ao ensino e às profissões superiores na Europa em perspectiva com as fases de desenvolvimento industrial ao longo dos séculos $\mathrm{IX}$ e $\mathrm{XX}$, em detrimento de considerações acerca das culturas nacionais, religiosas, ou da cronologia de regimes políticos.

Maria Rosa Lombardi trata dos desafios e barreiras com que se defrontam engenheiras no Brasil e na França tanto para ascender quanto no exercício de posições de comando, dentre os quais destaca o papel do grupo de profissionais do sexo masculino que "funcionaria como repositório de futuros gerentes e diretores" (p.400), a autolimitação pelas mulheres e a necessidade destas provarem continuamente sua competência profissional. Catherine Marry analisa, numa perspectiva da história das profissões, as condições de ascensão das mulheres no mundo acadêmico, sugerindo "deslocar a atenção das mulheres e de sua família para os mecanismos institucionais e as culturas disciplinares que geram (ou não) a discriminação sexual" (p.409). Constata que o fenômeno do "teto de vidro" aqui não se deve efetivamente a uma menor produtividade das mulheres, mas é constituído pelo acúmulo de "pequenas" defasagens ao longo do tempo, devidas em parte a "restrições interiorizadas ou sofridas contra a sua vontade pelas mulheres na vida privada, e mais ainda pelas barreiras estruturais no mundo acadêmico" (p.4|6).
Dentre os méritos deste livro destaca-se a amplitude de registros integrados às análises da relação entre mercado de trabalho e gênero: os estudos abrangem desde fatores econômicos, políticos e culturais, chegando a enfocar em alguns casos a ascendência nacional e mesmo a religião (embora esta questão em particular seja muito pouco explorada), até aqueles que dizem respeito à estrutura de políticas públicas e das profissões enquanto reprodutores, mas também produtores de representações e práticas generificadas e assimétricas. Enfim, além da abrangência em termos de contextos geográficos e sociais, a abordagem de aspectos e questões até então pouco explicitadas ou exploradas, no que concerne às relações de gênero no mercado de trabalho, fazem da presente coletânea obra de referência no seu campo de estudos.

Naira Pinheiro dos Santos,

Doutoranda em Ciências da Religião pela

Universidade Metodista de São Paulo Mandrágora/Netmal Núcleo de pesquisa em gênero e religião nairapinheiro@gmail.com

\section{PLANETA WEB 2.0: INTELIGENCIA COLECTIVA O MEDIOS FAST FOOD}

Cristóbal Cobo Romaní, Hugo Pardo Kuklinski

Barcelona: Grup de Recerca d'Interaccions Digitals, Universitat de Vic. Flacso; México DF: Flacso, 2007 (E-book acesso gratuito. http://www. planetaweb2. net/Versión 0.1)

\section{Web 2.0: entre a inteligência coletiva e os meios fast food}

$\mathrm{O}$ atual contexto de desenvolvimento da web e de seus conteúdos, bem como os fenômenos sociais que permeiam este processo, tem chamado a atenção de educadores 
e diversos outros profissionais, o que torna fundamental a leitura desse livro eletrônico. Os autores analisam vários aspectos da web, com o volume imenso que acumula de informações diversas, construídas por internautas-autores que consomem, produzem e publicam seus conteúdos e estruturas.

Daí surge a inquietação posta já no título do livro: seria a web um fenômeno social de inteligência coletiva, em que todos constroem com todos, ou simplesmente uma grande plataforma em que qualquer indivíduo, mesmo sem os referidos conhecimentos técnicos, se apropriaria rapidamente de informações prontas (fast food), exaltando assim o caráter amador da apropriação e das produções aligeiradas? Os próprios autores não consideram essas duas categorias - inteligência coletiva e meios fast food - como totalmente opostas, ou seja, para eles a inteligência coletiva é em parte impulsionada pelo amplo acesso à informação e, no caso específico da web 2.0, pela facilidade de manipulação e gestão autônoma. Dessa maneira, em vez de simplesmente responder à pergunta do título, exploram diversas características e suas potencialidades, abrindo espaço também para críticas e expectativas.

Este trabalho aparece como um aglutinador de ideias, que desenha um breve marco teórico e recompila um mapa de sítios, leituras e indicações para que os interessados possam percorrer, compreendendo esse momento evolutivo da World Wide Web. Para tanto, ao longo das 162 páginas, distribuídas em sete capítulos, são encontradas desde noções básicas sobre a web 2.0, como as principais referências, conceitos e críticas a essas idéias, até questões que ganham destaque entre os que trabalham com essa temática, como os serviços de mobilidade e a web semântica.

A análise passa por aspectos distintos, de forma complexa e imbricada com o contexto social contemporâneo, e, sem o intuito de apresentar respostas definitivas, pretende identificar algumas das nuanças do fenômeno da acumulação de informações e dar subsídios para que outros pesquisadores continuem aprofundando estudos nesse campo. De forma condizente com o que defendem como sendo uma nova cultura, Pardo e Romaní, mesmo distantes geograficamente, construíram colaborativamente a obra e a disponibilizaram sob uma licença Creative Commons' na web.

O livro começa com a discussão em torno do surgimento do conceito de web 2.0, a partir das idéias de O'Reilly ${ }^{2}$. Os autores definem o que chamam "sete princípios da web 2.0": a própria web como plataforma; o aproveitamento da inteligência coletiva; a gestão da base de dados como competência básica, sendo esse um forte valor agregador para o usuário; o fim do ciclo de atualizações de versões do software; modelos de programação rápida, buscando a simplicidade; a não-limitação do software a um único dispositivo; e as experiências enriquecedoras que surgem para os usuários. Os autores desenvolvem a idéia de uma "Lei de Moore semântica", referindo-se ao desenvolvimento e à velocidade de obsolescência de processadores e afirmando que, de forma semelhante, os conceitos e espaços da web se reconfiguram, dando espaço para tantos outros.

I. Creative Commons são opções flexíveis de licenças que garantem proteção e liberdade para artistas e autores, sendo que a autoria é preservada, mas o autor, que assinala ter "alguns direitos reservados" (ao contrário de "todos os direitos reservados"), permite que outros acessem, distribuam ou até reconfigurem sua obra, contribuindo substancialmente para a difusão e construção de novas informações (ver: http://www. creativecommons.org.br).

2. O'Reilly, T. What is web 2.0: design patterns and business models for the next generation of software. O'Reilly Publishing, 2005 (disponível em: http://www. oreillynet.com/pub/a/oreilly/tim/news/2005/09/30/ what-is-web-20.html; acesso em: 19 dez. 2008). 
Embora o termo web 2.0 seja usado por muitos, mais importante que a própria denominação, são os projetos fundamentados nessas características conceituais e técnicas, com destaque também à forma como as ideias fluem nesta web, de maneira a produzir pensamentos efêmeros, o que impede a construção de um marco conceitual estável. Acreditamos que, mesmo diante dessa complexidade, não há um rompimento com a web estática, mas sim uma emergência de novas práticas.

No segundo capítulo, destacamos o conceito de "intercriatividade" ou a constituição de um cérebro digital planetário. Para tanto, é preciso entender como as aplicações da web 2.0 oferecem novas oportunidades para a geração de conhecimentos e distribuição de informações, constituindo o princípio da coletivização do saber e da gestão do conhecimento. Atualmente ganham destaque as comunidades que praticam o intercâmbio da informação e a coletivização dos saberes e passa a ser esse um dos valores primordiais para a construção de conhecimento. Por sua vez, o conhecimento deixa de ser um bem privado e se torna um bem público e aberto, possibilitando que as pessoas se apropriem do que outros construíram, construam novos objetos e reconstruam os que já existem, troquem informações com outros sujeitos a fim de construir coletivamente e, ainda, participem ativamente da gestão das informações, mudando assim os pólos produtores e emissores.

Observa-se que a colaboração não nasce com a web, nem mesmo com a web 2.0. Esta última, porém, por meio de seus milhares de internautas-construtores, constitui-se a partir da colaboração e da construção conjunta. Isso, inclusive, altera a ordem social de consumo de informações "verdadeiras", ou pacotes prontos criados por seres e entidades autorizados para tal. Esse contexto colaborativo se forma na web e além dela, como um modo de trabalhar em redes de reciprocidade, sendo que a web 2.0 tem melhorado, simplificado e enriquecido as formas e os canais de comunicação entre as pessoas e os espaços de construção de informação.

O capítulo seguinte trata do desenvolvimento das aplicações na web e suas apropriações sociais, sua arquitetura. Essa estrutura é apresentada em quatro linhas fundamentais: redes sociais, conteúdos, organização social e inteligente da informação, além de aplicações e serviços. A fundamentação social é tida como uma característica transversal das aplicações web 2.0, facilitando a comunicação entre os integrantes da cibercultura. Chega-se, portanto, às possibilidades de fortalecimento de autoria, pois, embora emergindo de processos sociais, as informações são marcadamente produzidas por indivíduos reconhecidos como produtores de tais informações.

Sem abrir mão de uma visão crítica, Romaní e Pardo prosseguem relembrando os valores positivos que surgem a partir das idéias de O'Reilly e da evolução da web, mas não se furtam de fazer um levantamento dos posicionamentos contrários à idéia de web 2.0. Além de destacar a confusão tecnofóbica do progresso infinito, reconhecem que é difícil traçar um perfil honesto do tema, pois grande parte da indústria está preocupada em assegurar mercado e, em alguns casos, em impedir que produtos mais econômicos e eficientes ganhem espaços já cativos.

Sobre os consumidores como "desenvolvedores", na visão apresentada, destacamos o chamado "darwinismo digital", em que sobrevivem as melhores ferramentas; o analfabetismo digital como nova forma de discriminação; a vontade real de compreensão dos indivíduos, apesar da facilidade de documentação, informação e intercâmbio de conhecimentos; a possibilidade de viver, pensar e escrever em formato beta, acompanhando uma tendência aplicada 
aos softwares, que são disponibilizados sem serem fechados em pacotes ou versões estáticas, submetidos a constantes testes e modificações a partir das impressões dos usuários, o que dificulta a distinção entre conhecimento e ruído; a necessidade de saber lidar com a informação não prevista (serendipty); e o risco de charlatães que emplacam o amadorismo como bandeira, reivindicando inclusive o amadorismo coletivo, e propagam o mau uso da escrita colaborativa e da ética na internet.

Sobre esse aspecto, reforça-se a responsabilidade com que os autores tratam o texto. Mesmo pontuando os avanços e potencialidades da web, apontam algumas fragilidades, como nos modelos de negócios, nas construções comunitárias do conhecimento e nas precárias apropriações dessas tecnologias nas escolas. Apesar de adotarem a expressão "ferramenta", para referir-se a computadores e softwares de forma geral, os autores não se prendem a uma visão tecnicista, ao contrário, defendem a tecnologia como estruturante de novos processos sociais.

Com essa tônica iniciam o quinto capítulo, que começa tratando dos ganhos que surgem com a associação entre educação e tecnologias. Sob o aspecto quantitativo, há a possibilidade de ensinar a mais pessoas, e, sob o qualitativo, os novos recursos e o enriquecimento do processo de aprendizagem. Para os autores, a educação é uma das áreas mais beneficiadas com as novas tecnologias, em especial a web 2.0. Por isso, é primordial que se explore e aproveite as potencialidades dos novos recursos. A proposta é que não sejam encarados apenas como um novo meio, mas como um território potencial de colaboração em que um dos principais benefícios é o fato de não requerer uma alfabetização tecnológica avançada. Há, dessa forma, o estímulo à experimentação, reflexão, geração de novos conhecimentos e aprendizagem colaborativa.
Como princípios da contribuição específica da web 2.0 para o campo da educação, são apontados: aprender fazendo, aprender interagindo, aprender buscando e aprender compartilhando. Para tanto, blogs, wikis e repositórios são indicados como as aplicações da web 2.0 mais utilizadas nos processos educativos. Pardo e Romaní ainda mencionam o uso de VolP, arquivos de áudio na web, bibliotecas virtuais de consulta gratuita, buscadores e revisores ortográficos, dentre outros. Citam também experiências de aplicações da web 2.0 que obtiveram sucesso no campo educacional: iCamp, Moodle e seus blogs ${ }^{3}$, podcasts educativos para as universidades e m-learning (mobile learning, ou aprendizado móvel).

Embora não tenha sido citada pelos autores, é imprescindível ressaltar uma das características da web 2.0 que indicam necessárias mudanças na educação: os sujeitos deixam de ser usuários da web para serem construtores dela. Se a escola ensinava a responder ou buscar respostas prontas para perguntas também prontas, a web mostra que cada indivíduo deve ser pesquisador, protagonista, autor. Isso significa que a web, ao contrário de uma grande enciclopédia de consumo de informações, é o reflexo de cada um de nós, que transitamos por ela e, do modo como for, a construímos. A web é, portanto, cada um de nós! E, mais do que isso, somos todos nós juntos, ou o resultado de certa interação social, da qual surgem suas demandas e construções.

3. Ganham destaque, com a web2.0, os mashups, aplicações da web híbridas. Ou seja, conexões entre diferentes espaços da web, gerando uma nova aplicação. Os blogs do Moodle podem ser citados como exemplo disso, em que funcionalidades dos blogs são agregadas aos módulos do ambiente virtual de aprendizagem. Outro exemplo é o Sloodle, mix do Second Life - um metaverso em que os sujeitos se "travestem" de avatares e praticam uma "vida paralela" - com o Moodle, potencializando ambos e gerando aplicações que não eram possíveis antes. 
"Ubiquidade", "usabilidade" e "portabilidade" são conceitos que aparecem de maneira forte ao longo do capítulo seguinte, destacando o que consideramos, possivelmente, a principal tendência da convergência de mídias no momento: o hibridismo entre a telefonia móvel e a web 2.0. Os autores trazem a tecnologia $3 \mathrm{G}$ como um grande nicho de um mercado formado por adolescentes e adultos jovens, que logo se apropriaram de instrumentos criados originalmente para o consumo profissional e empresarial.

Da aliança natural entre mobile devices e as aplicações web 2.0, surgem pontos estratégicos, como a própria web sendo plataforma, a integração de conteúdos, a criação de uma ferramenta de consumo primário de informação e produção de conteúdos, tudo em um contexto pessoal e identitário. São esses consumidores que, segundo Planeta Web..., reforçam a crônica de uma convergência anunciada. $\bigcirc$ grande entrave, no sentido econômico, gira em torno de questões como a carência de um modelo ibero-americano de como agregar valor a esse novo produto e de quais conteúdos os consumidores querem nas plataformas móveis.

No final, encontramos a reafirmação de que a web 2.0 não é outra coisa que a atual fase do irrefreável e expansivo processo evolutivo da internet, que tem como característica essencial uma forte influência no social e do social. Ou seja, se havia uma preocupação com a produção de informação e sua armazenagem em grandes servidores, hoje a web é a plataforma e o computador doméstico é o servidor, sendo que os usuários se comunicam mais, trocam e produzem coletivamente e com tecnologias móveis. Isso gera uma nova problemática: como recuperar e interpretar os dados que são feitos de forma tão polifônica?

A grande tendência é a criação de sistemas inteligentes, máquinas que "conversam" entre si, bibliotecas que não sejam estáticas, trans- formando a internet em um sistema neuronal capaz de entender a si mesmo. Um passo para isso flutua em torno da web semântica, como os metadados ${ }^{4}$ - com os quais os próprios usuários classificam (com palavras-chave) os conteúdos por eles produzidos. Isso gera uma web mais intuitiva, aberta, eficaz e com sentido comum, capaz de operar com bases de dados distribuídas, por meio de linguagens naturais. Esse, porém, ainda é um grande desafio, com várias questões que precisam de solução, como, por exemplo, a dificuldade de interpretar o que é informação relevante ou apenas ruído, ou mesmo como interligar os significados das palavras escritas das tantas formas como são expressas pelas pessoas. Mesmo assim, pode-se afirmar que o processo evolutivo da web tende a apontar para repositórios interconectados de metadados interoperáveis, resultado do contínuo fenômeno social que abarca esse desenvolvimento.

É possível que neste momento o conceito de web 2.0 esteja passando por novas reformulações, se partirmos da ideia da Lei de Moore semântica. Entendemos essa web como um ecossistema vivo e, por isso, em constante transformação, criação e recriação. Apesar de lançado em 2007 e de tratar de uma temática em constante ebulição, este é um livro fundamental para aqueles que desejam compreender o atual panorama da web. Não só profissionais da comunicação e informação, mas principalmente educadores, além de todos aqueles que de alguma maneira lidam com a construção/difusão do conhecimento.

Consideramos Planeta web 2.0... excelente não apenas pelas discussões que impulsiona pelo tratamento dado ao assunto, uma visão

4. Um conceito derivado da mesma ideia é a folksonomia, uma taxonomia criada pelos sujeitos e que se interliga com as tantas outras formas de classificação e organização, criando uma lógica horizontal, social e inteligente de organização de conteúdos cada vez mais fluidos. 
conscientemente crítica e clara da realidade. Mas, principalmente, por oferecer um cuidadoso levantamento e sistematização de referências para quem se interessar pelo aprofundamento no tema. Além disso, Pardo e Romaní constroem, por meio do livro, um metalaboratório, uma vez que além de disponibilizá-lo na web, incentivam os leitores a participar de wikis, twiters e tantos outros espaços que são alimentados e estruturados por todos que ali passam. Assim, os autores deixam de ser apenas emissores, e os leitores não são encarados somente como consumidores. Todos são parte de um processo fluido e dinâmico. Isso é web 2.0!

\section{Adriane Lizbehd Halmann}

Doutorado no Programa de Pós-Graduação em Educação e participante do Grupo de Pesquisa em Educação, Comunicação e Tecnologias, da Universidade Federal da Bahia
Bolsista do Conselho Nacional de Desenvolvimento Científico e Tecnológico adriane_halmann@yahoo.com.br

\section{Rita Virginia Argollo}

Doutorado no Programa de Pós-Graduação em Educação e participante do Grupo de Pesquisa em Educação, Comunicação e Tecnologias, da Universidade Federal da Bahia Bolsista do Conselho Nacional de Desenvolvimento Científico e Tecnológico rvargollo@yahoo.com.br

\section{Géssica de Oliveira Aragão}

Aluna do Curso de Pedagogia e participante do Grupo de Pesquisa em Educação, Comunicação e Tecnologias da Universidade Federal da Bahia Bolsista do Programa Institucional de Bolsas de Iniciação Científica gessica_aragao@yahoo.com.br 